\title{
Detection of PIK3/AKT pathway in Moroccan population with triple negative breast cancer
}

Farah Jouali ${ }^{1,2^{*}}$, Nabila Marchoudi ${ }^{1}$, Salwa Talbi ${ }^{3}$, Basma Bilal ${ }^{4}$, Mohamed El Khasmi ${ }^{2}$, Houria Rhaissi ${ }^{2}$ and Jamal Fekkak ${ }^{1}$

\begin{abstract}
Background: Triple Negative Breast Cancer (TNBC) is an aggressive form of breast cancer, that represents 10-20\% of all breast carcinomas and characterized by the lack of a specific cell surface marker compared to other breast cancer subtypes. Due to the absence of molecular markers for TNBC his treatment options remains limited, without proven targeted therapies, which emphasize the need for discovering molecular markers that could be targeted for patient treatment, An important number of TNBC cases harbor aberrations in the phosphoinositide 3-kinase (PI3K) pathway, leading to constitutive activation of the downstream signaling pathway. Among mechanisms of PI3K enhancement, PIK3CA mutations are most frequently ( 30\%) observed, along with protein loss of PTEN and AKT activation by phosphorylation (pAkt). Therefore, we propose to analyze clinocopathologic and molecular characteristics of PI3K/AKT/PTEN pathway in Moroccan triple negative breast cancer patients.
\end{abstract}

Methods: We conducted a retrospective study of 39 patients diagnosed with triple negative breast cancer between early 2013 and 2016. In this study, we used the Ion Personal Genome Machine (PGM) and Ion Torrent Ampliseq Cancer panel to sequence hotspot regions from PIK3CA, AKT and PTEN genes to identify genetic mutations in 39 samples of TNBC subtype from Moroccan patients and to correlate the results with clinical-pathologic data.

Results: All patients were female with a median age of 46 years from (34-65). Most patients have had invasive ductal carcinoma (84.6\%) and 69.2\% of them were grade III SBR. Among the 39, 9 were right sided tumor patients and the remaining 30 were left-sided. Mutational analysis of PIK3CA gene was achieved in all TNBC patients. PIK3CA hotspot mutations were detected in 5/39 of TNBC (13\%), in detail, among these 5 TNBC patients, one harbored mutation in exons 9 and four in exon 20.

Conclusion: The PI3KCA gene is highly activated and plays a crucial role in the pathogenesis of TNBC more, therefore, may be a potential therapeutic target to improve outcomes in patients.

Keywords: PIK3CA, AKT, PTEN, Triple negative breast cancer, PI3K pathway

\section{Background}

Triple-negative breast cancer (TNBC) is a highly diverse group of cancers defined by the lack of oestrogen, progesterone, and ERBB2 receptors expression, it may account for $10-20 \%$ of all newly diagnosed breast cancer cases [1], and it mostly arises in younger and premenopausal women [2].

\footnotetext{
*Correspondence: frh_0712@hotmail.com

'Anoual Laboratory of Radio-Immuno Analysis, Angle Blvd Alexandrieet Blvd Anoual, 20360 Casablanca, Morocco

${ }^{2}$ Laboratory of Pathophysiology and Molecular Genetics, Ben M'Sik Faculty of Science, 7955 Casablanca, Morocco

Full list of author information is available at the end of the article
}

TNBC is generally associated with larger size, higher histological grade, more advanced disease stage and a tendency towards local and visceral metastases showing the worse prognosis compared to other breast cancer subtypes $[3,4]$.

Although many reports claim that TNBCs respond to chemotherapy better than other types of breast cancer, his prognosis remains poor [3] and this is due to shortened disease-free interval in the adjuvant and neoadjuvant setting and a more aggressive course in the metastatic setting [4]. Therefore, establishing a new effective molecular therapeutic approach in killing TNBC

(c) The Author(s). 2018 Open Access This article is distributed under the terms of the Creative Commons Attribution 4.0 International License (http://creativecommons.org/licenses/by/4.0/), which permits unrestricted use, distribution, and 
cells is crucially required to improve TNBC patients outcome [5]. This emphasize the importance of molecular studies in this breast cancer subtype.

Since the development of molecular technologies tell now many genomic studies has been conducted in purpose of better understanding the molecular nature of triple negative breast cancer, these studies have shown that TNBC could be classified into numerous independent subtypes remarkably heterogeneous at the genomic level [6], They further shed light into the large number of genes and major cellular pathways potentially involved in TNBC tumorigenesis. In the last decade, there has been intensive research to define the relative contributions of these genes and cellular pathways in TNBC and to identify therapeutic targets for TNBC based on genomics [7].

The PI3K/AKT is one of the most frequently altered pathway in breast cancer.in TNBC is the second most altered after TP53 gene. This pathway is implicated in many cell cycle process like cell survivor or proliferation [8], these process are ensured by serine and/or threonine phosphorylation of this pathway downstream substrates [9]. The key proteins involved are phosphatidylinositol 3-kinase (PI3K) and Akt/Protein Kinase B. PI3K protein is an heterodimer consists of two subunits: p110 catalytic subunit encoded by

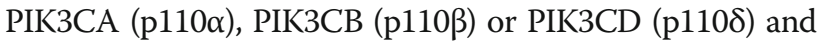
one p85 regulatory subunit encoded by PIK3R1 (p85 $\alpha$ ),

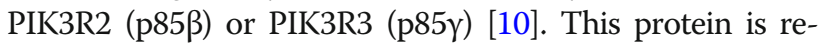
sponsible for the phosphorylation of Akt, a serine/threonine kinase through the phosphorylation of phosphatidylinositol 4,5 bisphosphate (PIP2), to phosphatidylinositol 3,4,4-triphosphate (PIP3). The phosphorylation of AKT initiate a downstream signaling cascade that is regulated by The tumor suppressor Phosphatase and tensin homolog deleted on chromosome ten (PTEN) this protein reverses the effects of PI3K by dephosphorylating the same site on membrane phosphatidylinositols that is phosphorylated by PI3K $[11,12]$. In cancer genomic alterations in one of this pathway key proteins like gene mutations or duplications cause cell cycle dysregulation leading to cancer genesis, and because genomic aberrations can predict responsiveness to targeted therapies, and because multiple PI3K pathway members are frequently aberrant in breast tumors, targeting this pathway may provide a highly effective therapeutic approach $[13,14]$.

PIK3CA mutations are the most common genetic alteration of this pathway. Approximately $80 \%$ of PIK3CA somatic mutations are located in two common hotspot regions [15], the helical that contains E542K or E545K mutations in exon 9 and the kinase that carries H1047R or H1047L mutation in exon 20. The mechanism by which they promote constitutive PI3K signaling remains unclear [16]. Both types of mutation were indicated to be gain-of-function and transforming activity $[17,18]$.
On the other hand, genomic aberrations observed in the PI3K pathway in breast cancer include also activating alterations, involving the AKT and loss/mutation of PTEN [19, 20].The prevalence of AKT1 mutation (E17K) in breast cancer is $8 \%$, which has been shown to lead to notable kinase activity than that of wild-type AKT1 [21]. Therefore, AKT integrates various upstream inputs and triggers downstream network activities [17].While PTEN mutations are relatively uncommon in breast cancer $(<5 \%)$, PTEN protein loss is frequent $(\sim$ $30 \%)[12,22]$. This loss is reported to be caused by various mechanisms, such as promoter methylation, loss of heterozygosity, and regulation at the RNA or protein level. $[12,22,23]$

The current study aim to analyze the clinocapathologic and molecular characteristics of PI3K/AKT/PTEN pathway in Moroccan triple negative breast cancer patients.

\section{Patients and methods \\ Patients}

The current study involved TNBC patients diagnosed at the University Hospital Center of Casablanca and Marrakech, Morocco, between early 2013 and 2016. The primary inclusion criterion was an adequate fresh tumor obtained from a resected tumor sample. The enrolled patients met the following criterion: (I). Patients with pathologically proved TNBC. (II). Cases with the complete clinical, pathological and follow-up data. (III) Patients between the age of 20 and 65. Informed consent was obtained from patients to use their surgical specimens and clinic-pathological data for research purposes.

This retrospective study was performed at Anoual Laboratory of Radio-Immuno Analysis, Casablanca, Morocco, where the samples were processed for NGS.

\section{Methods \\ DNA extraction}

Tumors consisting of over $50 \%$ malignant cells were dissected under microscopy from 4-mm unstained sections by comparison with a hematoxylin and eosin (HE) stained slide, and genomic DNA was extracted using a Qiagen DNA FFPE Tissue kit (Qiagen, Hilden, Germany) according to the manufacturer's instructions. After extraction, DNA concentration was measured using the Qubit dsDNA HS (High Sensitivity) Assay kit and the Qubit ${ }^{\circ}$ Fluorometer (Invitrogen; Thermo Fisher Scientific, Inc., Waltham, MA, USA).

\section{Library preparation}

Ten nanograms of DNA was used for preparing amplicon library using Ion AmpliSeq ${ }^{\mathrm{Tm}}$ Library kit 2.0 (Ion Torrent; Thermo Fisher Scientific, Inc.) and Ion Ampli$\mathrm{Seq}^{\mathrm{Ts}}$ Cancer hotspot panel (Ion Torrent; Thermo Fisher Scientific, Inc.), according to manufacturer's instructions. 
This panel contains 207 primer pairs in a single tube and surveys hotspot regions of 50 oncogenes and tumor suppressor genes. The genes included in the panel were: ABL1, AKT1, ALK, APC, ATM, BRAF, CDH1, CDKN2A, CSF1R, CTNNB1, EGFR, ERBB2, ERBB4, EZH2, FBXW7, FGFR1, FGFR2, FGFR3, FLT3, GNA11, GNAS, GNAQ, HNF1A, HRAS, IDH1, JAK2, JAK3, IDH2, KDR, KIT, KRAS, MET, MLH1, MPL, NOTCH1, NPM1, NRAS, PDGFRA, PIK3CA, PTEN, PTPN11, RB1, RET, SMAD4, SMARCB1, SMO, SRC, ST11, TP53 and VHL. Each library was barcoded using Ion Xpress ${ }^{\mathrm{TM}}$ Barcode Adapters kit (Ion Torrent; Thermo Fisher Scientific, Inc.).

\section{Template preparation by emulsion polymerase chain reaction ( $P C R$ )}

The amplified and purified libraries were diluted to a final concentration of $100 \mathrm{pM}$. Template preparation by emulsion PCR was carried out using the Ion PGM ${ }^{\mathrm{TM}}$ Template Hi-Q OT2 200 kit, followed by the Ion OneTouch $^{\mathrm{Tm}} 2$ System (Ion Torrent; Thermo Fisher Scientific, Inc.), according to manufacturers' protocol.

The polyclonal percentage and quality of the enriched, template-positive ISPs was determined using the Ion Sphere Quality Control Kit (Ion Torrent; Thermo Fisher Scientific, Inc.). The optimal amount of template-positive ion sphere particles (ISPs) is 10-30\%. ISPs were then enriched for template positive ISPs using Dynabeads MyOne Streptavidin C1 beads (Invitrogen; Thermo Fisher Scientific, Inc.) in the Ion OneTouch ${ }^{\mathrm{\tau}} \mathrm{ES}$ instrument (Ion Torrent; Thermo Fisher Scientific, Inc.).

\section{Ion torrent PGM sequencing}

Finally, sequencing was carried out on the Ion Personal Genome Machine System PGM (Ion Torrent; Thermo Fisher Scientific, Inc.) using Ion $316^{\mathrm{TM}}$ Chips and the Ion $\mathrm{PGM}^{\mathrm{TM}}$ Sequencing Hi-Q Kit v2, according to the manufacturer's guidelines. For a sequence variant to be considered authentic, a sequencing coverage of $100 \mathrm{X}$ reads was used as a minimum requirement in the present study.

\section{Bioinformatics and statistical analysis for AmpliSeq}

Data from the sequencing runs were initially processed Torrent Suite software v5.4 (Ion Torrent; Thermo Fisher Scientific, Inc.) to generate sequence reads, filter, and remove poor signal-profile reads using the reference genomic sequence (hg19) of target genes.

Coverage analysis and variant calling was performed with Torrent Variant Caller plugin software v5.4. Following data analysis, annotation of single-nucleotide variants, insertions, deletions and splice site alterations was performed using the Ion Reporter Server System (Thermo Fisher Scientific, Inc.) and the Ingenuity ${ }^{\circ}$ Variant Analysis Software (Qiagen, Inc.).

\section{Statistical analysis}

Statistical analysis of clinic-pathologic data was performed using IBM SPSS Statistics ver. 21 (IBM Co., Armonk, NY). Chi-square ( $\left.x^{2}\right)$ test and Fisher's exact test were performed to assess significance of the association between variables (PIK3CA, AKT and PTEN mutations in TNBC patients) and clinical characteristics. Statistical difference was defined as $P<0.05$.

\section{Results}

In total, 47 TNBC patients were enrolled in this study. Of the 47 patients, targeted DNA sequencing was performed on 39 patients only. Samples from 8 patients did not undergo next generation sequencing due to DNA extraction failure. TNBC samples were characterized by ER, PR, and HER2 negativity, with ki67 proliferation index ranging from 30 to $90 \%$. Clinico-pathological characteristics of the patients are summarized in Table 1. All patients were female with a median age of 46 years from (34-65). Among the 39, 9 were right sided tumor patients and the remaining 30 were left-sided. Most patients were invasive ductal carcinoma and had high histological grade (grade III). The clinical-pathologic data of TNBC according to mutational status of PIK3CA included in this study are also reported in Table 1.

\section{Mutational analysis of PIK3CA, AKT and PTEN gene}

Mutational analysis of PIK3CA gene was achieved in all TNBC patients. PIK3CA hotspot mutations were detected in $5 / 39$ of TNBC (13\%), in detail, among these 5 TNBC patients, oneharbored mutation in exons 9 and four in exon 20 .

Apropos the analysis of PIK3CA exon 9, involving the helical domain of PIK3CA gene, our results showed the presence of one somatic mutation c.1633G > A p.E545K, which was revealed in $1 / 39$ TNBC $(2.5 \%)$. On the other hand, the mutational analysis of PIK3CA exon 20, involving the kinase domain of PIK3CA gene, showed the presence of one hotspot mutation c.3140A > G p.H1047R, which was identified in 4/39 TNBC (10.2\%). No case had mutations in both exons and coexistence of two or more mutations. In contrast, no AKT1 and PTEN mutations were detected in 39 patients that were successfully sequenced.

The correlation of PIK3CA alteration status with clinical data was investigated in TNBC patients. (Table 1). In short, there were no associations between mutational status of PIK3CA with age $(p=0.542)$, histopathological type $(p=0.09)$, localization $(p=0.729)$ or histological grade $(p=0.639)$. No significant associations were found between PIK3CA mutational status and clinico-pathological features according to TNBC subgroup. 
Table 1 Clinic-pathologic and biologic data of the TNBC patients according to mutational status of PIK3CA

\begin{tabular}{|c|c|c|c|c|c|c|c|c|}
\hline & \multirow[t]{2}{*}{ Variables } & \multicolumn{2}{|l|}{ Overall } & \multicolumn{2}{|c|}{ PIK3CA wild type } & \multicolumn{2}{|c|}{ PIK3CA mutated } & \multirow[t]{2}{*}{$P$-value } \\
\hline & & effective & $\%$ & effective & $\%$ & effective & $\%$ & \\
\hline \multirow[t]{2}{*}{ Age range } & $<40$ & 11 & 28.2 & 9 & 23.07 & 2 & 5.1 & 0.542 \\
\hline & $>40$ & 28 & 71.7 & 25 & 64.1 & 3 & 7.6 & \\
\hline \multirow[t]{2}{*}{ Localization } & Left breast & 30 & 76.9 & 25 & 64.1 & 5 & 12.8 & 0.09 \\
\hline & Right breast & 9 & 23.0 & 9 & 23.1 & 0 & 0 & \\
\hline \multirow[t]{2}{*}{ Histopathologic type } & Ductal carcinoma invasive & 33 & 84.6 & 29 & 74.3 & 4 & 10.2 & 0.729 \\
\hline & Lobular carcinoma invasive & 6 & 15.3 & 5 & 12.8 & 1 & 2.5 & \\
\hline \multirow[t]{2}{*}{ Grade SBR } & $\|$ & 12 & 30.7 & 10 & 25.6 & 2 & 5.1 & 0.639 \\
\hline & III & 27 & 69.2 & 24 & 61.5 & 3 & 7.6 & \\
\hline \multirow[t]{3}{*}{ Ki67 } & $<20 \%$ & 0 & 0 & 0 & 0 & 0 & 0 & 0.254 \\
\hline & $20-50 \%$ & 8 & 20.5 & 6 & 15.3 & 2 & 5.1 & \\
\hline & $>50 \%$ & 31 & 79.4 & 28 & 71.7 & 6 & 15.3 & \\
\hline
\end{tabular}

\section{Discussion}

The phosphatidylinositol 3-kinase (PI3K/Akt) signaling cascade is crucial to divergent physiological processes, which include cell cycle progression, differentiation, and metabolism [24]. The PI3K/Akt pathway aberrations are common in breast cancer, pointing to a critical role for this signaling pathway in breast carcinogenesis [22]. This pathway is frequently activated in triple negative breast cancer (TNBC), via molecular abnormalities such as PIK3CA mutations or loss of PTEN function.As has been observed previously, PIK3CA oncogene mutations were more common in TNBC unlike Akt1 and PTEN mutations [25-27].

In the present study, the mutation rate of PIK3CA in triple negative breast cancer was $13 \%$ (5/39). Two different PIK3CA mutations were identified: c.1633G $>$ A p.E545K in helical domain encoded by exon 9 and c.3140A > G p.H1047R in the kinase domain encoded by exon 20. Mutations p.E545K and p.H1047Rhave been found in previous studies to be the most prevalent in breast cancer and are associated with an increase activity in the PI3K pathway. These findings are consistent with those of Chen $\mathrm{YH}$ et al. study, which have found a prevalence of $16 \%(6 / 38)$ [28]. This was confirmed by Milis et al. study comprising a larger cohort of 702 TNBC patientsin whom 93 had mutations in the PIK3CA gene (ie 13\%) [26].

The rate obtained in our study remains lower than that reported by Cossu-Rocca et al., who in a cohort of 97 TNBC patients, 23\% were found to have PIK3CA mutation [29]. This rate were further supported by Kriegsmann et al. who showed 22,1\% PIK3CA mutation rate in a cohort of 104 TNBC patients [30].

These differences in rates can be explained by the difference in the studied populations, particularly AfricanAmericans who have a low percentage of PI3KCA gene mutations compared with the Caucasian population.
This hypothesis was observed in the study of Ademuyiwaet al [31].

We were interested in testing the relationship between PIK3CA mutational status and other known clinicpathologic markers (table1). No association was identified regarding PIK3CA mutations and patient age, histopathological type or grade of the tumors. These results are similar to those of Paul S Weisman et al. [32].

Besides PIK3CA gene, AKT1 and PTEN gene also known to be altered in PIK3 pathway. In the present study, no mutations were detected in AKT1 and PTEN genes. These results are consistent with those of Stemke-Hale et al. who in a cohort of 20 TNBC tumors showed no mutation in PTEN gene [22]. Furthermore, the same study also investigated the AKT1 E17K mutation prevalence in a cohort of 111 TNBC patients and found no mutations [22].Another study performed by $\mathrm{K}$. Hashimoto et al., confirm our results since no mutations was detected in 75 TNBC patients [33].

Mutations in the PTEN gene are rarely seen in breast cancers $(<5 \%)$, however the loss of expression of PTEN protein (promoter methylation, loss of heterozygosity) is widespread [10]. Expression analysis of PTEN by immunohistochemistry revealed a loss of expression in $69 \%$ of triple negative tumors (372 cases) according to a study by Millis et al. [26] and $77 \%$ of cases according to the study by Shaham Beg et al. [34].

Mutations of the AKT1 gene have been reported in 1.4 to $8 \%$ (mean $\sim 4 \%$ ) of infiltrating ductal carcinomas $[22,35]$. The E17K mutation of the AKT1 gene is considered a potential diagnostic biomarker for breast cancer [36], which led us to search for this mutation in our study. However, no mutations were detected and this was supported by two large sequencing studies who also failed to find mutations in the Akt1 gene [37, 38].

The absence of mutations in Akt1 and PTEN genes does not necessarily means that there is not any other alterations in epigenetics that might cause problems in 
the protein. Therefore, PTEN and AKT expression and post-transcriptional status in TNBC patients may be explored.

The PI3K-AKT-mTOR pathway is clearly a fundamental pathway involved in carcinogenesis (proliferation, apoptosis, differentiation and neo-angiogenesis). The presence of multiple mediators in the PI3K signaling pathway means that there are several specific targets to achieve cell arrest and to limit the toxicity of therapies [39].

In recent years, several inhibitors have emerged and have been the subject of clinical trials. Use of PI3K pathway inhibitors as single-agent therapies has proved minimally effective in somediseases [40]. The complexity of the PI3K pathway with multiple feedback mechanisms explains some of the drug resistance. Combination drug therapies that simultaneously target these escape mechanisms will likely lead to the greatest clinical success [41]. The first drugs entering the clinical trials were the inhibitors of mTOR (Rapamycin) and its analogues [40].

\section{Conclusion}

TNBC is a heterogeneous subtype. Its complexity at the clinical and genetic levels illustrates that no single treatment approach will produce universal benefit in this disease.The PI3K/AKT pathway is highly activated and plays a crucial role in the pathogenesis of TNBC and, therefore, may be a potential therapeutic target to improve outcomes in patients.

\section{Abbreviations}

ER: Estrogen Receptor; FFPE: formalin-fixed paraffin-embedded;

HE: hematoxylin and eosin; HER-2: Human Epidermal Growth Factor Receptor 2; HS: High Sensitivity; mTOR: mechanistic target of rapamycin; OT2: One Touch 2; PGM: Personal Genome Machine; PI3K : Phosphoinositide 3-kinase; PIK3CA: Phosphatidylinositol-4,5-Bisphosphate 3-Kinase Catalytic Subunit Alpha; PR: Progesterone Receptor; PTEN: Phosphatase and Tensin homolog deleted on chromosome ten; TNBC: Triple Negative Breast Cancer

\section{Acknowledgments}

We thank the Anoual laboratory of Radio-Immuno Analysis, Casablanca and Laboratory of Pathophysiology and Molecular Genetics, Ben M'Sik Faculty of Science, Casablanca for their support and help.

\section{Funding}

The authors have no support or funding to report.

\section{Availability of data and materials}

The datasets analyzed during the current study and a list of material requirement will be available from the corresponding author on reasonable request.

\section{Consent for publication}

Not applicable

\section{Authors' contributions}

FJ contributed for the study conception, design, writing of the manuscript, acquisition of data and analysis. NM participated to the design of the study and helped with data and analysis. NM and JF contributed to the revision of the manuscript. ST and BB contributed to the data collection and have given approval of the final manuscript. ME, HR and JF contributed to the design of the study and interpretation of the data and approved the analyzed literature data and have given approval of the final manuscript. All authors read and approved the final manuscript.

Ethics approval and consent to participate

The study was approved by the Ethics Committee for Research of the University Hassan II. All participants gave a written informed consent to participate in the study.

\section{Competing interests}

The authors declare that they have no competing interests.

\section{Publisher's Note}

Springer Nature remains neutral with regard to jurisdictional claims in published maps and institutional affiliations.

\section{Author details}

${ }^{1}$ Anoual Laboratory of Radio-Immuno Analysis, Angle Blvd Alexandrieet Blvd Anoual, 20360 Casablanca, Morocco. ${ }^{2}$ Laboratory of Pathophysiology and Molecular Genetics, Ben M'Sik Faculty of Science, 7955 Casablanca, Morocco. ${ }^{3}$ Department of Oncology, Center Hospital University Mohammed VI, 40080 Marrakech, Morocco. ${ }^{4}$ Department of Pathology, Center Hospital University Ibn Rochd, 20100 Casablanca, Morocco.

Received: 13 February 2018 Accepted: 12 September 2018 Published online: 18 September 2018

\section{References}

1. Morris GJ, et al. Differences in breast carcinoma characteristics in newly diagnosed African-American and Caucasian patients: a single-institution compilation compared with the National Cancer Institute's Surveillance, Epidemiology, and End Results database. Cancer. 2007;110(4):876-884. https://doi.org/10.1002/cncr.22836. [PubMed] [Cross Ref].

2. Carey LA, Perou CM, Livasy CA, et al. Race, breast cancer subtypes, and survival in the Carolina breast cancer study. JAMA. 2006;295(21):2492-502 PubMed.

3. Azim HA, Jr, Michiels S, Bedard PL, Singhal SK, Criscitiello C, Ignatiadis M, Haibe-Kains B, Piccart MJ, Sotiriou C, Loi S. Elucidating prognosis and biology of breast cancer arising in young women using gene expression profiling. Clin Cancer Res 2012;18:1341-1351.

4. Liedtke C, Mazouni C, Hess KR, Andre F, Tordai A, Mejia JA, et al. Response to neoadjuvant therapy and long-term survival in patients with triplenegative breast cancer. J Clin Oncol. 2008;1275-1281(PubMed):26.

5. Haffty BG, et al. Locoregional relapse and distant metastasis in conservatively managed triple negative early-stage breast cancer. J ClinOncol. 2006;24(36): 5652-5657. doi: 10.1200/JCO.2006.06.5664. [PubMed] [Cross Ref].

6. Kreike B, van Kouwenhove M, Horlings $H$, Weigelt B, Peterse $H$, Bartelink $H$, et al. Gene expression profiling and histopathological characterization of triple-negative/basal-like breast carcinomas. Breast Cancer Res. 2007;9:R65. [PMC free article] [PubMed].

7. Burstein MD, Tsimelzon A, Poage GM, Covington KR, Contreras A, Fuqua SA, et al. Comprehensive genomic analysis identifies novel subtypes and targets of triple-negative breast cancer. Clin Cancer Res. 2015;21:1688-1698. [PMC free article] [PubMed].

8. Tokunaga E, Oki E, Egashira A, Sadanaga N, Morita M, Kakeji Y, et al. Deregulation of the Akt pathway in human cancer. Curr Cancer Drug Targets. 2008:8(1):27-36. 18288941.

9. Myers MG Jr, Backer JM, Sun XJ, Shoelson S, Hu P, Schlessinger J, Yoakim M, Schaffhausen B, White MF 1992. IRS-1 activates phosphatidylinositol 3'kinase by associating with src homology 2 domains of p85 proc Natl Acad Sci 89: 10350-10354 [PMC free article] [PubMed].

10. Hennessy BT, Smith DL, Ram PT, Lu Y, Mills GB. Exploiting the PIJK/AKT pathway for cancer drug discovery. Nat Rev Drug Discov. 2005;4:988-1004.

11. Cantley LC. The phosphoinositide 3-kinase pathway. Science. 2002;296: $1655-7$.

12. Wellcome Trust Sanger Institute. Catalogue of somatic mutations in cancer (COSMIC). In: Accessed march 9; 2010. http://www.sanger.ac.uk/genetics/ CGP/cosmic/.

13. Vanhaesebroeck B, Guillermet-Guibert J, Graupera M, Bilanges B. The emerging mechanisms of isoform-specific PI3K signalling. Nat Rev Mol CellBiol. 2010;11:329-41. 
14. Samuels $Y$, Wang Z, Bardelli A, et al. High frequency of mutations of the PIK3CA gene in human cancers. Science. 2004;304:554.

15. Comprehensive molecular portraits of human breast tumours Nature 490 : 61-70,2012 Cancer Genome Atlas Network Crossref, Medline.

16. Samuels $Y$. High frequency of mutations of the PIK3CA gene in human cancers. Science. 2004;304:554

17. Zhao JJ, Liu Z, Wang L, Shin E, Loda MF, Roberts TM. The oncogenic properties of mutant p110a and p110 3 phosphatidylinositol 3-kinases in human mammary epithelial cells. Proc Natl AcadSci U S A. 2005;102(51): 18443-18448. [PMC free article] [PubMed].

18. Isakoff SJ, Engelman JA, Irie HY, et al. Breast cancer-associated PIK3CA mutations are oncogenic in mammary epithelial cells. Cancer Res. 2005: 65(23):10992-1000 [PubMed].

19. Banerji S, Cibulskis K, Rangel-Escareno C, Brown KK, Carter SL. Frederick AM, et al.Sequence analysis of mutations and translocations across breast cancer subtypes. Nature. 2012;486:405-9.

20. Network CGA. Comprehensive molecular portraits of human breast tumours. Nature. 2012;490:61-70.

21. Carpten JD, Faber AL, Horn C, et al. A transforming mutation in the pleckstrin homology domain of AKT1 in cancer. Nature. 2007;448:439-44.

22. Stemke-Hale K, Gonzalez-Angulo AM, Lluch A, et al. An integrative genomic and proteomic analysis of PIK3CA, PTEN, and AKT mutations in breast cancer. Cancer Res. 2008;68(15):6084-91.

23. Jézéquel $P$, Loussouarn $D$, Guérin-Charbonnel C, Campion L, Vanier $A$, Gouraud W, et al. Gene-expression molecular subtyping of triple-negative breast cancer tumours: importance of immune response. Breast Cancer Res. 2015;17:43. [PMC free article] [PubMed].

24. Yuan TL, Cantley LC. PI3K pathway alterations in cancer: variations on a theme. Oncogene. 2008;27:5497-510.

25. Arsenic R, Lehmann A, Budczies J, Koch I, Prinzler J, Kleine-Tebbe A, et al. Analysis of PIK3CA mutations in breast cancer subtypes. AppllmmunohistochemMolMorphol. 2014;50-56(PubMed):22.

26. Millis SZ, Gatalica Z, Winkler J, Vranic S, Kimbrough J, Reddy S, et al. Predictive biomarker profiling of $>6000$ breast cancer patients shows heterogeneity in TNBC, with treatment implications. Clin Breast Cancer. 2015. April 28 pii: S1526-8209(15)00098-1. https://doi.org/10.1016/j.clbc. 2015.04.008 [PubMed].

27. Gonzalez-Angulo AM, Chen H, Karuturi MS, Chavez-MacGregor M Tsavachidis S, Meric-Bernstam F, et al. Frequency of mesenchymal-epithelial transition factor gene (MET) and the catalytic subunit of phosphoinositide3-kinase (PIK3CA) copy number elevation and correlation with outcome in patients with early stage breast cancer. Cancer. 2013; 119(1):7-15. https:// doi.org/10.1002/cncr.27608 [PMC free article][PubMed].

28. Yu-Hsiang Chen, Bradley A. Hancock, Jeffrey P. Solzak, et al.Next-generation sequencing of circulating tumor DNA to predict recurrence in triplenegative breast cancer patients with residual disease after neoadjuvant chemotherapy.NPJ Breast Cancer. 2017;3:24. https://doi.org/10.1038/s41523017-0028-4. [Free PMC Article][PubMed].

29. Cossu-Rocca P, Orrù S, Muroni MR, Sanges F, Sotgiu G, Ena S, Pira G, Murgia L, Manca A, Uras MG, Sarobba MG, Urru S, De Miglio MR, et al.Analysis of PIK3CA Mutations and Activation Pathways in Triple Negative Breast Cancer. PLoS One. 2015 Nov 5;10(11):e0141763. https://doi.org/10.1371/journal.pone. 0141763. eCollection 2015. [Free PMC Article].

30. Kriegsmann M, Endris V, Wolf T, Pfarr N, Stenzinger A, Loibl S, Denkert C, Schneeweiss A, Budczies J, Sinn P, Weichert W, et al. Mutational profiles in triple-negative breast cancer defined by ultradeep multigene sequencing show high rates of PI3K pathway alterations and clinically relevant entity subgroup specific differences.Oncotarget. 2014 Oct 30; 5(20):9952-65. [Free PMC Article].

31. Ademuyiwa FO, Tao Y, Luo J, Weilbaecher K, Ma CX. Differences in the mutational landscape of triple-negative breast cancer in African Americans and Caucasians. Breast Cancer Res Treat. February 2017; 161(3):491-9. https://doi.org/10.1007/s10549-016-4062-y.

32. Weisman PS, Ng CK, Brogi E, Eisenberg RE, Won HH, Piscuoglio S, De Filippo MR, loris R, Akram M, Norton L, Weigelt B, Berger MF, Reis-Filho JS, Wen HY. Genetic alterations of triple negative breast cancer by targeted nextgeneration sequencing and correlation with tumor morphology. ModPathol. 2016 May;29(5):476-488. https://doi.org/10.1038/modpathol. 2016.39. Epub 2016 Mar 4. https://doi.org/10.1038/modpathol.2016.39.

33. Hashimoto K, Tsuda H, Koizumi F, Shimizu C, Yonemori K, Ando M, Kodaira M, Yunokawa M, Fujiwara Y, Tamura K. Activated PI3KJAKT and MAPK pathways are potential good prognostic markers in node-positive, triplenegative breast cancer. Ann Oncol. 2014 Oct;25(10):1973-9. https://doi.org/ 10.1093/annonc/mdu247 Epub 2014 Jul 9.

34. Beg S, Siraj AK, Prabhakaran S, Jehan Z, Ajarim D, Al-Dayel F, Tulbah A, AlKuraya KS. Loss of PTEN expression is associated with aggressive behavior and poor prognosis in middle eastern triple-negative breast cancer. Breast Cancer ResTreat. 2015 Jun;151(3):541-53. https://doi.org/10.1007/s10549015-3430-3 Epub 2015 May 16.

35. Bleeker FE, Felicioni L, Buttitta F, Lamba S, Cardone L, Rodolfo M, Scarpa A, Leenstra S, Frattini M, Barbareschi M, Grammastro MD, Sciarrotta MG, Zanon C, Marchetti A, Bardelli A. AKT1(E17K) in human solid tumours. Oncogene. 2008 Sep 18;27(42):5648-50. https://doi.org/10.1038/onc.2008.170 Epub 2008 May 26.

36. Rudolph M, Anzeneder T, Schulz A, Beckmann G, Byrne AT, Jeffers M, Pena C, Politz O, Köchert K, Vonk R, Reischl J. AKT1 (E17K) mutation profiling in breast cancer: prevalence, concurrent oncogenic alterations, and bloodbased detection. BMC Cancer. 2016 Aug 11;16:622. https://doi.org/10.1186/ s12885-016-2626-1.

37. Sjoblom T, Jones S, Wood LD, et al. The consensus coding sequences of human breast and colorectal cancers. Science. 2006;268-74(PubMed):314.

38. Greenman C, Stephens P, Smith R, et al. Patterns of somatic mutation in human cancer genomes. Nature. 2007; 446:153-8. [PMC free article] [PubMed].

39. Gordon V, Banerij S. Molecular pathways: PI3K pathway targets in triplenegative breast cancers. Clin Cancer Res. 2013 Jul 15;19(14):3738-44. https://doi.org/10.1158/1078-0432.CCR-12-0274 Epub 2013 Jun 7.

40. Chan S, Scheulen ME, Johnston S, Mross K, Cardoso F, Dittrich C, et al. Phase II study of temsirolimus (CCl-779), a novel inhibitor of mTOR, in heavily pretreated patients with locally advanced or metastatic breast cancer. J Clin Oncol. 2005:23:5314-22.

41. Baselga J, Campone M, Piccart M, Burris HA, Rugo HS, Sahmoud T, et al. Everolimus in postmenopausal hormone-receptor-positive advanced breast cancer. N Engl J Med 2012;366:520-9. [CrossRef] [PubMed] [Google Scholar]

\section{Ready to submit your research? Choose BMC and benefit from:}

- fast, convenient online submission

- thorough peer review by experienced researchers in your field

- rapid publication on acceptance

- support for research data, including large and complex data types

- gold Open Access which fosters wider collaboration and increased citations

- maximum visibility for your research: over $100 \mathrm{M}$ website views per year

At BMC, research is always in progress.

Learn more biomedcentral.com/submissions 